\title{
PROCESSO PARTICIPATIVO NO PAISAGISMO DE UMA NASCENTE URBANA
}

PROCESO PARTICIPATIVO EN EL PAISAJISMO DE UN MANANTIAL URBANO

\section{PARTICIPATIVE PROCESS IN THE LANDSCAPE OF AN URBAN SPRING}

\author{
RESENDE, KELER MARA G. DE
}

Mestre, Universidade Vale do Rio Verde - UninCor, Três Corações, keler.resende@hotmail.com

\section{ALCANTRA, ELIANA}

Doutora, Universidade Vale do Rio Verde - UninCor, Três Corações, lialcantra@yahoo.com.br

MARQUES, ROSÂNGELA F. P. V.

Doutora, Universidade Vale do Rio Verde - UninCor, Três Corações, roeflorestal@hotmail.com

RIOS, MARIA ROBERTA D. L.

Graduação Arquitetura e urbanismo, Universidade Vale do Rio Verde - UninCor, Três Corações, mdellaluciarios90@gmail.com

\begin{abstract}
RESUMO
Com este trabalho objetivou-se propor um projeto paisagístico sustentável de uma nascente urbana, localizada em Três Corações-MG. Além da proposição de medidas técnicas, este estudo trata-se também de uma proposta de sensibilização e mobilização da população moradora do entorno, com a intenção de gerar o sentimento de pertencimento e consequentemente a proteção e conservação da área. Foram utilizados processos participativos embasados pelas teorias da organicidade das organizações humanas. O projeto paisagístico foi elaborado conforme a estrutura da NBR n¹6636-2/2017, dividido em quatro etapas consecutivas e complementares: levantamento de dados, estudo preliminar, anteprojeto e projeto executivo. 0 conceito adotado para o projeto paisagístico foi o da sustentabilidade, com gestão participativa, objetivando a diminuição do impacto ambiental além de baixos custos e baixa necessidade de manutenção. 0 processo participativo foi importante na conscientização da comunidade em relação a riqueza que a área da nascente significa e envolveu a comunidade nas tomadas de decisão para a elaboração do projeto paisagístico de revitalização, inspirando o sentimento de pertencimento e de corresponsabilidade. 0 projeto paisagístico fornece as informações necessárias para a sua implantação e servirá de instrumento na captação de recursos para sua efetivação.
\end{abstract}

PALAVRAS-CHAVE: revitalização; paisagem; sustentabilidade; tecnologia social.

\section{RESUMEN}

Este trabajo tuvo como objetivo proponer un diseño de paisaje sostenible para un manantial urbano, ubicado en Três Corações, Minas Gerais, Brasil. Además de proponer medidas técnicas, este estudio es también una propuesta para concienciar y movilizar a la población que habita el entorno, con la intención de generar el sentimiento de pertenencia y en consecuencia la protección y consenvación de la zona. Se utilizaron procesos participativos basados en las teorías de la organicidad de las organizaciones humanas. El diseño del paisaje se elaboró según la estructura del NBR n¹6636-2 / 2017, dividido en cuatro etapas consecutivas y complementarias: recolección de datos, estudio preliminar, diseño preliminar y diseño ejecutivo. El concepto adoptado para el diseño de paisaje fue el de sostenibilidad con gestión participativa, con el objetivo de reducir el impacto ambiental además de bajos costos y bajos requerimientos de mantenimiento. El proceso participativo fue importante para sensibilizar a la comunidad sobre la riqueza que significa el área del manantial e involucró a la comunidad en la toma de decisiones para la elaboración del proyecto de revitalización del paisaje, inspirando el sentimiento de pertenencia y corresponsabilidad. El diseño de paisaje proporciona la información necesaria para su implementación y servirá como un instrumento para recaudar fondos para su implementación.

PALABRAS CLAVES: revitalización; paisaje; sostenibilidad; tecnología social.

\section{ABSTRACT}

This work aimed to propose a sustainable landscape design for an urban spring, located in Três Corações, Minas Gerais, Brazil. In addition to proposing technical measures, this study is also a proposal to raise awareness and mobilize the population living in the surrounding area, with the intention of generating the feeling of belonging and consequently the protection and conservation of the area. To be worked on, participatory processes based on the theories of the organicity of human organizations were used. The landscape design was prepared according to the structure of NBR $n^{0} 16636-2 / 2017$, divided into four consecutive and complementary stages: data collection, preliminary study, preliminary design and executive design. The concept adopted for the landscape design was that of sustainability, with a participatory process, aiming at reducing the environmental impact in addition to low costs and low maintenance requirements. The participatory process was important in raising the community's awareness of the wealth that the spring area means and involved the community in decision-making for the elaboration of the landscape revitalization design, inspiring the feeling of belonging and co-responsibility. The landscape design provides the necessary information for its implementation and will serve as an instrument in raising funds for its implementation.

KEYWORDS: revitalization; landscape; sustainability; social technology. 


\section{INTRODUÇÃO}

O entorno das nascentes d'água desempenha um importante papel socioambiental. Depende dele a boa saúde das nascentes, a estabilidade geológica da área, a biodiversidade local, a riqueza do solo e o fluxo gênico de fauna e flora, e, por extensão, a existência dos regatos e cursos d'água que alimentam os rios, imprescindíveis ao equilíbrio ecológico e à viabilidade da vida nas cidades. Por isso, a legislação brasileira de águas e de florestas classifica as nascentes e seu entorno como Área de Preservação Permanente - APP (VIEIRA, 2019).

No sistema ecológico das nascentes, a vegetação é um dos principais elementos. Formada por plantas adaptadas a terrenos muito úmidos, sujeitos a inundações periódicas, a vegetação típica de nascentes combate naturalmente os processos de erosão, que podem ser graves em áreas de aeração. Ela também ameniza a temperatura, purifica o ar, filtra poluentes, colabora com a regulação do ciclo da água e é alimento para a fauna silvestre (BRASIL, 2012).

Em Três Corações, cidade em que foi realizada esta pesquisa, o rio Verde é um personagem principal e se encontra devastado. Entre os trechos do rio Verde com mata ciliar degradada, há um na região conhecida como "começo da Cotia", de urbanização das mais antigas da cidade, em terreno que pertence ao Estado de Minas Gerais no bairro Vila Viana. A área integra o patrimônio da Escola Estadual Godofredo Rangel e está cedida à agremiação desportiva amadora América Futebol Clube. O campo de futebol "do América", antigo na comunidade da Vila Viana, foi aberto em área do terreno que hoje é considerada pela legislação como uma Área de Preservação Ambiental, pois em seu extremo oposto ao da margem do rio, o sopé de um barranco com cerca de sete metros de altura abriga uma nascente. Consta que a nascente, inominada na comunidade a que pertence, já teve fluxo de água perene e lago com peixes. Mas as perturbações da paisagem nos últimos anos a fizeram recrudescer.

Dado que o problema seja, para além de ambiental, cultural, optou-se por um tratamento metodológico de envergadura socioambiental. A partir do conceito de "paisagem", tomado por empréstimo à geografia, foi elaborado um projeto paisagístico participativo. Pereira e Matos (2015) enfatizaram a relevância do planejamento em ambientes a partir da participação da comunidade, pois consideram que planejar esses espaços em conjunto possibilita uma relação de pertencimento da população com tais espaços. Para Ramalho (2007) trabalhar com percepção, sensibilização e apropriação de um espaço, resulta em paisagens de qualidade, com identidade e vínculos com seus usuários e, portanto, contribuem para as expectativas desses usuários, para a preservação dessas paisagens e para autonomia da gestão e a construção da cidadania.

Houve colaboração direta das comunidades desportiva e escolar em todas as fases de elaboração da revitalização da nascente, o que fez do processo, não só conhecido, mas significativo para o público diretamente abrangido.

O projeto paisagístico considerou possibilidades de revitalização e conservação da nascente próxima à Escola Godofredo Rangel em Três Corações, MG, tendo sido feita a opção pela proposta de revitalização, com os critérios do baixo custo, da redução efetiva do impacto ambiental negativo na área e da menor demanda por manutenção futura no espaço revitalizado. Com o trabalho objetivou-se elaborar um projeto paisagístico sustentável no entorno de uma nascente, localizada no terreno da Escola Estadual Godofredo Rangel, no município de Três Corações, MG, com a intenção de revitalizá-la buscando a participação da comunidade. Tal processo é relatado neste artigo

\section{UM PROJETO FUNDAMENTADO NO RECONHECIMENTO DA COMUNIDADE E NA PARTICIPAÇÃO}

\section{Caracterização da área}

Situada em área pública, pertencente ao Estado de Minas Gerais, a nascente objeto deste estudo fica no bairro Cotia, à rua Cabo Benedito Alves, n 416, no sopé de um barranco situado na parte posterior de um terreno com aproximadamente $35 \mathrm{mil} \mathrm{m}^{2}$. O terreno pertence à Escola Estadual Godofredo Rangel, é limitado pelas coordenadas $21^{\circ} 41^{\prime} 58.9^{\prime \prime S}$ e $45^{\circ} 15^{\prime} 48.5^{\prime \prime}$ W (FIGURA 1), e resultou de duas doações de terrenos da Prefeitura de Três Corações ao Estado de Minas Gerais, ambas realizadas no ano de 1972. Sua testada principal faz divisa com a rua Cabo Benedito Alves, e os limites dos fundos são delimitados por uma das margens do rio Verde.

A Escola foi edificada em 1974, quando a área foi dividida em três diferentes níveis topográficos, separados por taludes. No nível mais baixo, acessível pela rua General Osório, lateral, há um campo de futebol nivelado por aterramento, cedido pela escola estadual à associação desportiva amadora América Futebol Clube, inaugurado no ano de 1984. 
Figura 1: Localização da nascente urbana no município de Três Corações, sul de Minas Gerais.

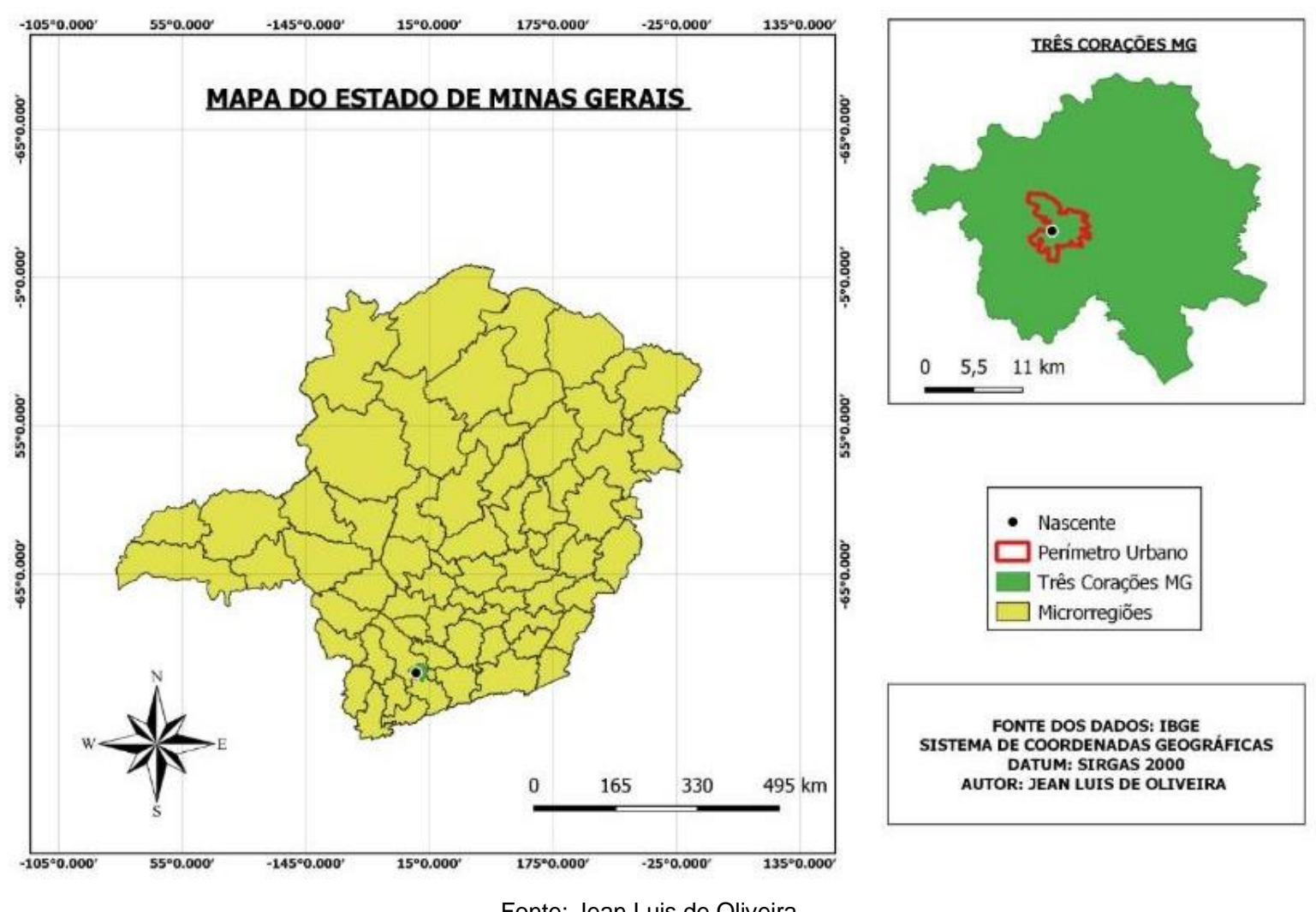

\section{Percepção ambiental e envolvimento da comunidade}

O trabalho foi realizado após a aprovação do projeto submetido ao Comitê de ética de Pesquisa com Humanos, Parecer $n^{\circ}$ 3.251.627.

No levantamento e análise da percepção ambiental a respeito da nascente e de seu entorno pelas comunidades circunvizinhas foi adotado um processo participativo, conforme metodologia desenvolvida por Ramalho (2007) e Barbosa e Mota (2013). Foram atividades de interação da autora do projeto com as comunidades, sendo quatro delas em forma de atividade de extensão comunitária, que foram aprovadas pela Pró-Reitoria de Pós-Graduação, Pesquisa e Extensão da UninCor.

Os temas das atividades do processo participativo foram, em ordem de aplicação: apresentação do projeto de pesquisa ao corpo docente; reunião com a direção da escola; primeiros encontros com a gestão do América Futebol Clube; segunda reunião com o diretor da escola; um manejo inesperado no campo do América; reunião com uma liderança comunitária; primeira reunião com o grupo de professores; visita à nascente; segunda reunião com grupo de professores; palestra para alunos sobre a revitalização da nascente (atividade de extensão comunitária); plantio participativo (atividade de extensão comunitária); um conflito próximo a nascente; apresentação no "América" do anteprojeto de revitalização da nascente (atividade de extensão comunitária); apresentação aos professores do anteprojeto da revitalização da nascente (atividade de extensão comunitária). Dado o número reduzido de encontros possíveis, buscou-se o reconhecimento e a valorização dos chamados canais informais de comunicação das comunidades, tanto na construção dos diagnósticos como para fazer o processo de revitalização da nascente significativo para os envolvidos.

\section{Projeto paisagístico sustentável}

A técnica executiva do projeto paisagístico foi elaborada em conformidade com os princípios da sustentabilidade, e atendendo à Norma Técnica NBR 16636-2/2017, da Associação Brasileira de Normas Técnicas (ABNT), que disciplina a elaboração e o desenvolvimento de projetos técnicos.

Para a formulação das etapas foram considerados dois itens: o diagnóstico e o processo participativo. Ressalte-se que a cada etapa foi feita uma avaliação que pode, eventualmente, determinar mudanças no decurso do processo. Além disso, para a formulação das etapas também concorreram: as exigências do 
conceito de paisagismo sustentável, o enfoque na mitigação do impacto ambiental, com baixo custo de implantação e baixo grau de manutenção.

A primeira etapa, levantamento de dados, foi destinada à coleta das informações que representam as condições preexistentes da nascente, reunidas no interesse da instrução da elaboração do projeto paisagístico. Foram levantados dados físicos, biológicos, sociais e culturais pertinentes à nascente. Em seguida procedeu-se ao estudo preliminar destinado ao dimensionamento inicial dos conceitos do projeto necessários à compreensão da configuração do espaço. As informações colhidas na etapa anterior foram examinadas e sistematizadas. No limite, o estudo preliminar colaborou para harmonizar o binômio teoria e prática. Para dar tratamento aos dados colhidos na etapa anterior, foi elaborado um estudo de setorização do espaço com seus acessos principais, e um estudo do sistema de revegetação.

A etapa seguinte foi o anteprojeto que consistiu na proposição da solução do problema, com as respectivas definições de distribuição de funções e de áreas de intervenção, sob forma de desenhos. Nesta altura da elaboração, partindo dos estudos produzidos na etapa anterior, foram localizados os acessos secundários, as cercas, os caminhos, o aceiro e a vegetação. O espaço denominado "Bosque" obteve um projeto de revegetação com localização e determinação das espécies a serem plantadas.

O projeto executivo reuniu as informações e detalhes necessários à implantação e manutenção do espaço objeto desta proposta de revitalização, e foi produzido com um nível de detalhamento suficiente para orientar os respectivos serviços de implantação. Neste sentido, o projeto executivo contemplou a planta de situação, a planta de implantação com elementos não vegetais e a planta de implantação botânica, além dos quadros com indicação da vegetação proposta, especificando seu nome popular e científico. Contemplou, também, o plano de manejo, fazendo a indicação da continuação do processo participativo nos processos de implantação e manutenção, e ainda foram apresentados os principais itens necessários para a adequada implantação da proposta.

\section{O DESENVOLVIMENTO DO PROCESSO PARTICIPATIVO}

\section{$A$ introdução do projeto perante a comunidade escolar}

A integração da população aos processos de recuperação ambiental cumpre a função de aumentar a proteção da área, seja ela pública ou não. É preciso haver um pacto social em torno da área protegida para que ela não sofra com o vandalismo ou outras formas de depredação pela sociedade. Os valores que fazem da natureza objeto de proteção legislativa só existem a partir da conscientização dos sujeitos. Nesta tomada de consciência, a ideia de que a natureza necessita ser protegida cede lugar para a noção de que se trata no limite de proteger a vida humana (BARBOSA; MOTA, 2013).

No final da tarde do dia 18 de março de 2019 aconteceu a primeira etapa dos processos participativos. O projeto de pesquisa foi apresentado ao corpo docente da Escola Estadual Godofredo Rangel, que abriga a nascente. $O$ encontro durou 20 minutos e se realizou durante a reunião pedagógica semanal da diretoria com os 40 professores da escola. Uma abrangência adequada em se tratando de um contato inaugural. A grande maioria destes professores é servidor efetivo do estado de Minas Gerais, com atribuição de um cargo completo - dedicação de $20 \mathrm{~h}$ - à escola. Arranjo que favorece o comprometimento deles com a paisagem da escola e, logo, com a nascente.

Durante a apresentação, foram comunicados os aspectos técnicos da pesquisa e foi feito o convite à participação direta dos docentes nas atividades de elaboração do projeto de revitalização da nascente. Foi possível detectar que, apesar da dedicação há anos da maioria dos professores à escola, havia quem desconhecesse completamente a existência da nascente. Alguns já tinham ouvido a respeito de sua existência, mas não sabiam em que parte do terreno ela se encontra. E, entre estes, muitos concordaram que souberam do manancial a partir da reiteração da mesma história: sobre um diretor da escola que, há anos, se atolou no brejo que se forma eventualmente no entorno da nascente. A percepção inicial da nascente pela comunidade docente se mostrou relativamente fria. Exceto por um grupo de cinco professores, além do diretor da escola e da vice-diretora do turno da manhã, se prontificaram a colaborar com o projeto. Em conversa com eles após a reunião, apurou-se que então não havia nenhuma ação institucional ou cultural que mantivesse a comunidade escolar em relação com a nascente.

Foi possível apurar, também, que a área da nascente está cedida a outra entidade, de natureza desportiva, que administra e utiliza o campo de futebol vizinho à nascente. O que ajuda a compreender porque a comunidade escolar não se sente responsável pela APP. 


\section{Reunião com a direção da escola: o histórico dos conflitos sociais}

Na manhã do dia 16 de abril de 2019, na sala da direção geral, foi iniciado o processo de oficialização desta pesquisa frente à comunidade da Escola Estadual Godofredo Rangel, junto do diretor geral da escola Prof. C. e da vice-diretora do turno matutino Prof ${ }^{a}$. O. Durante as tratativas, a pesquisadora destacou que um dos aspectos mais importantes da proposta consistiria na construção participativa de soluções para a nascente. Pessoalmente sensível ao processo participativo, a direção franqueou à pesquisadora imediato e amplo acesso à escola e à nascente. E informou quem é o responsável pela operação geral do América Futebol Clube: o Sr. M.

A pesquisadora acertou com a direção escolar que, uma vez aceito o projeto pelo colegiado, formalizaria o processo participativo da comunidade escolar como um projeto de extensão comunitária da universidade. Definiu-se que o projeto de extensão se realizaria em encontros com as comunidades desportiva, discente e docente escolar, a partir dos quais todos os interessados poderiam se informar e contribuir com as etapas iniciais da revitalização da nascente.

A pedido da pesquisadora, a direção escolar ofereceu uma breve panorâmica dos conflitos sociais que perpassam a nascente. Segundo o diretor, desde a década de 1980 a área da nascente está cedida a uma agremiação desportiva amadora, o América Futebol Clube. Ali, além do campo de jogo, há um sobrado, o prédio da administração do clube e os vestiários com banheiros. Junto das edificações, uma placa comemorativa informa que o clube foi inaugurado em 1984. O que permite supor que à mesma época foi feita uma canalização do curso d'água da nascente sob o campo de futebol.

O diretor mencionou ainda dois debates importantes. O primeiro deles remete ao episódio, em passado recente, em que um ex-diretor teria sido denunciado por permitir o corte de eucaliptos nos fundos dos prédios da escola. A madeira decorrente do corte das árvores jazia nos fundos da escola, interditada como prova judicial. Motivado pela denúncia, o segundo debate vinha ocupando o atual grupo gestor da escola há meses: providenciar a doação definitiva da área da nascente à agremiação desportiva.

Ora, de uma APP (da nascente) às margens de outra (do rio), ambas degradadas, não deveria ser dada outra finalidade que não a de ser uma Área de Preservação Permanente. Além disto, a operação de doação resultaria no recrudescimento da responsabilização formal pelo espaço, uma vez que na escola há um quadro de pessoal comprometido com as normas da gestão pública. Dando-se a propriedade à associação desportiva isso se perderia.

\section{Primeiro encontro com a gestão do América Futebol Clube: falta de institucionalidade}

O primeiro contato com a agremiação desportiva aconteceu por acaso. Durante as visitas técnicas da pesquisadora à nascente, apareceu para conversar o Sr. M, responsável pela área. Homem de hábitos informais, ele não se apresentou como um dirigente do clube desportivo, tampouco tratou de qualquer assunto envolvendo a área. Sem intimidade com a burocracia institucional que envolve o uso ou a posse de uma área pública do Estado, ele demonstrou ter bom trânsito com a comunidade desportiva e com a diretoria da escola.

Desde os primeiros momentos o Sr. M. demonstrou sensibilidade para a questão da nascente e recebeu muito bem a proposta de revitalização da área, sobretudo quanto à expectativa de recuperação do olho d'água original. Mas, provavelmente por uma noção reducionista do problema, não sinalizou qualquer preocupação com a mata ciliar.

O Sr. M informou que sua relação é mais com o futebol do que com a entidade. Ele se apresentou como uma das pessoas que "fazem tudo sozinhas" para manter o clube ativo. Os treinamentos e jogos são conduzidos por voluntários, com o apoio de doações. Nas palavras dele, os anos de 1990 foram os melhores para a agremiação, pois havia empresas que patrocinavam equipes amadoras espalhadas pela cidade. Há 20 anos aquele cenário não se repete. Indiferentemente a isso, o Sr. M defendeu a doação definitiva da área ao América Futebol Clube. Ele mencionou a existência de um documento que seria o passo inicial do processo de doação, muito embora não o tenha apresentado ao longo das tratativas, nem tenha sabido dizer com clareza de que documento se trata.

As conversas com o Sr. M trouxeram à tona o outro lado da moeda na problemática da doação do terreno. É possível conjecturar que deve haver uma institucionalidade da agremiação desportiva, ainda que mínima. Um estatuto em que está nomeada uma diretoria deve estar arquivado em alguma gaveta, distante do funcionamento cotidiano do América Futebol Clube. Neste quadro de baixa institucionalidade, a responsabilidade com o meio ambiente tende a ter menos aderência. 


\section{Segunda reunião com o diretor da escola: temores}

$\mathrm{Na}$ tarde de 18 de agosto, o diretor da escola voltou a verbalizar sua preocupação com as condições legais do manejo da nascente. A pesquisadora esclareceu que o manejo seria projetado conforme métodos científicos adequados e respeitando-se a legislação pertinente. Foi necessário afirmar que, no limite, o projeto ofereceria às comunidades desportiva e escolar a chance de obterem como recompensa o usufruto das normas ambientais que regem a área.

Tranquilizado pelas explicações, o diretor da escola reportou que, no passado, o terreno da escola integrava uma fazenda, época em que a nascente produzia um lago de tal tamanho que nele se podia pescar. Esta breve reunião reforçou a hipótese de que o grupo gestor da escola nutria uma preocupação de autopreservação profissional sobreposta à responsabilidade ambiental. Dado importante, pois se interpõe à sensibilização para o valor social e ambiental da nascente.

\section{Um manejo inesperado na APP: culturas de uso}

Durante o recesso escolar da segunda quinzena de julho de 2019, a cobertura vegetal do solo posterior ao campo de futebol foi retirada. Com a mesma extensão da linha de fundo do campo principal, o manejo degradou ainda mais as condições do solo e da flora no local. Segundo relatos de populares, a máquina pertencia ao Poder Público, foi trazida por um servidor público ligado ao "América" e o manejo se destinaria à criação de um mini-campo de jogo.

De acordo com o Sr. M., a área foi arada para controle dos carrapatos; uma solução improvável, sobretudo pelo conflito ambiental que acirra. Quanto à responsabilidade pela operação, o Sr. M. não admitiu ter encomendado a aração. Consultada, a direção da escola informou que não encomendou nem autorizou a interferência na área. E que havia tomado medidas a respeito disso junto à Secretaria da Educação. A pronta reação sinalizou nova sensibilidade para a questão. Assim, o episódio atestou a tendência da comunidade desportiva de executar os planos de intervenção na APP, até pela dificuldade de reconhecê-la como tal. Ficou evidente também que a APP está sujeita a interferências sem autorização do Estado. E o episódio reforçou ainda a preocupação com o que pode resultar da doação futura do terreno à agremiação desportiva.

\section{Primeira reunião com o grupo de professores}

Ao final da reunião escolar da tarde de 19 de agosto de 2019 foram destinados 30 minutos para que nove professores se dedicassem ao primeiro encontro do grupo docente que adotou projeto de recuperação da nascente. Além deles, participaram da reunião a pesquisadora e sua orientanda M., graduanda em Arquitetura e Urbanismo.

Após uma breve introdução sobre a problemática da revitalização de nascentes, o grupo se informou sobre os critérios de escolha das espécies arbóreas para recompor a zona ripária e a mata ciliar. O professor V., de Geografia, se mostrou conhecedor do processo de reflorestamento. A professora de Português Srâ. V. se ofereceu para providenciar esterco bovino e mudas de uma fazenda que frequenta, além de pedir a alguns alunos que trouxessem mudas. A pesquisadora se comprometeu a fazer uma lista de mudas adequadas para a área da nascente. Ficou marcada uma visita ao local para o dia 26 do mesmo mês, com alunos e professores envolvidos em atividades relativas ao projeto de revitalização da nascente.

A professora R. de História, que sempre residiu nas imediações da escola, relatou que em sua infância os pais alertavam e proibiam os filhos de caminharem pela área da nascente, pois o brejo oferecia o risco de atolamento.

Às $19 \mathrm{~h}$, alguns professores precisaram ir para suas salas de aula. Ficou combinada a criação de um grupo de Whatsapp para comunicação. Como os demais preferiram seguir com o debate, a reunião continuou por mais 20 minutos, tempo em que se apresentou a representação gráfica da nascente e seu entorno, utilizada como recurso para sensibilizar os participantes para situação atual (naquele momento) e para as potencialidades do espaço.

Nesta altura, é oportuno registrar a importância de os projetos externos às escolas públicas buscarem inserção nas rotinas escolares já existentes, como estratégia para evitar-se o conflito de agendas. Se, por um lado, não foi possível ter reuniões com o corpo docente dedicadas exclusivamente ao projeto, por inegável falta de tempo hábil para agendas extras, por outro lado, uma vez que houve a conformação das atividades ao calendário escolar, a aderência da proposta foi ampla. 


\section{Visita à nascente com o grupo de professores que adotou o projeto: memória}

No dia 26 de agosto, além da pesquisadora, da orientanda de iniciação científica e de quatro professoras do grupo de apoio à nascente, compareceu também à visita à nascente o Sr. O., servidor público aposentado e "vereador sênior" em projeto de educação política da Câmara Municipal tricordiana.

A visita à nascente teve como objetivo principal a sensibilização dos professores para a importância deles na questão da conservação, frente aos conflitos que envolvem a nascente. A ocasião serviu também para debater as melhores estratégias de inserção da questão da revitalização da nascente nas rotinas docentes. Resultado deste debate, o dia do replantio comunitário de mudas na mata ciliar, a primeira ação de recuperação da área, foi incorporado a um sábado letivo previsto no calendário. Uma data anterior ao cronograma original, mas oportuna porque mobilizaria não só os alunos, mas também seus familiares, que participam deste sábado letivo anual e já tradicional.

A presença de um "vereador sênior" na visita à nascente foi uma estratégia para sensibilizar a Câmara de Vereadores para a emergência de se recuperar a nascente. A Câmara Sênior tem trânsito com as Comissões Temáticas Permanentes da Câmara, dentre elas a de Meio Ambiente.

Dos quatro professores que visitaram a nascente, três não haviam estado ali antes. A quarta professora já tinha visitado o espaço, mas para trazer o filho para treinar futebol, ocasião em que não deu pela existência da nascente. Assim, e uma vez que se tratava de quatro docentes efetivos da escola, a visita inaugurou um importante traço na memória da comunidade escolar.

As professoras ficaram surpresas com a pequena quantidade de água no local da nascente e entenderam a gravidade da situação. A professora de Geografia observou a grande quantidade de mudas espontâneas presentes na parte mais vegetada, bem próximo aos olhos d'água, e identificou algumas espécies. A presença de tais mudas deixou evidente o potencial regenerativo do local. Isto foi decisivo para a fase de estudo preliminar do projeto paisagístico, posto que a área foi classificada como "de regeneração natural".

\section{Segunda reunião com o grupo de professores: plano de manejo participativo}

A reunião sobre a revitalização da nascente que deveria ter integrado a reunião pedagógica de 09 de setembro de 2019, não aconteceu conforme o planejado. Uma emergência institucional se interpôs. E o jeito foi proceder com a reunião na sala dos professores, com parte do grupo, três professores, a vice-diretora e a pesquisadora, enquanto o diretor se ocupou das atividades emergenciais com o colegiado no auditório.

A pesquisadora elaborou uma minuta de plano de manejo. Como o tempo era muito curto, apenas as atividades participativas foram discutidas: a preparação do plantio de mudas e sua execução. $O$ plano de manejo viria a ser alterado ainda muitas vezes pela via digital.

Para o sábado letivo com alunos e familiares, a professora de Biologia se comprometeu a dar uma breve aula sobre o ciclo hidrológico. A professora de Geografia e a pesquisadora se responsabilizaram pela prévia provisão e proteção das mudas na capoeira, para o dia da atividade. A pesquisadora e dois funcionários da escola, o Sr. A e o Sr. J, ficaram responsáveis pela preparação do solo e das mudas no dia anterior ao plantio.

Notadamente, o planejamento do plantio participativo serviu para popularizar diversas questões de manejo entre os professores e para intensificar o sentido da recuperação da nascente para a comunidade escolar. Nas discussões os professores entraram em relação com as imposições da legislação pertinente, entre as quais a ilegalidade implicada na recuperação da mata ciliar com espécies que não as típicas. Eles também compartilharam suas preocupações com a sensibilidade das zonas ripárias, e discutiram a problemática do barranco que se eleva da área da nascente à escola. As áreas mais adequadas a se tornarem um caminho entre a associação desportiva e a escola foram mapeadas.

Mesmo com os imprevistos, a atividade proporcionou que começasse a circular na comunidade escolar um esboço do que viria a ser a nascente revitalizada. A pesquisadora estimulou os professores a compartilharem e discutirem com seus colegas os pontos críticos do plano de manejo, como estratégia para densificar a presença do projeto na comunidade escolar.

\section{Palestra para alunos sobre a revitalização da nascente}

No dia 01 de outubro de 2019, duas turmas de alunos da escola estadual, de segundo e terceiro ano do segundo grau, matutino, num total de 63 participantes, debateram a questão da nascente a partir de uma palestra sobre a revitalização. Foi também da primeira atividade de extensão comunitária no âmbito desta pesquisa. 
A palestra abordou os principais conceitos relativos à revitalização da nascente, bem como apresentou a área do manancial por fotos e ilustrações. Os estudantes tiveram acesso à fundamentação ecológica da intervenção e aos principais relatos colhidos na vizinhança sobre a nascente. Além disso, os estudantes puderem compreender como as intervenções pretendidas para a área da nascente operam para que ela recupere suas qualidades hidrológicas. Eles foram convidados a colaborar com o plantio planejado de mudas de vegetação pioneira, marcado para o chamado "Dia D" (que correspondeu ao sábado letivo com a participação da família).

Muito embora o alunado tenha expressado intimidade com a questão ambiental, poucos deles sabiam da existência da nascente. Entre os poucos que já tinham notícias da nascente, a grande maioria soube ao praticar futebol na agremiação desportiva. Neste sentido, a reunião teve um efeito geral de introduzir a nascente ao corpo discente da escola.

No debate especulou-se sobre o uso social da nascente a partir de um questionário com três perguntas: "A APP da nascente pode ser utilizada para benefício próprio?"; O que deve ser feito para que a APP seja utilizada de maneira efetiva e sustentável?" e "Que nome você sugere para a nascente de vocês?".

Os nomes sugeridos para a nascente se vinculavam em geral à escola. Assim, Godofredo Rangel, Godofredo, Godô, Polivalente, Poli e até Polinascente foram as sugestões mais comemoradas. Sobre o uso, ficou clara a preocupação em usufruir com cuidado. Os alunos propuseram medidas como a colocação de bancos e mesas; a promoção de piqueniques, sonecas e atividades de relaxamento; a utilização da água para consumo, nas refeições da escola e para nadar. Houve também a preocupação de: "certificar-se que o grêmio estudantil acompanhe semanalmente se a nascente está desenvolvendo bem."

\section{Dia D: o plantio participativo}

O "Dia D", um sábado letivo dedicado à integração entre a escola e as famílias, acontece anualmente e oferece intensa agenda de atividades. No contexto da programação do dia 05 de outubro de 2019, a última hora da manhã foi destinada ao replantio da vegetação da nascente. No dia anterior, pesquisadora e os jardineiros da escola prepararam o coroamento e a abertura das covas, com separação de solo superior e inferior para cada uma delas.

No "Dia D", por volta das $11 \mathrm{~h} 20,25$ pessoas, entre alunos, familiares, professores e diretores se encaminharam do auditório da escola para a área da nascente. Junto ao olho d'água houve uma explicação rápida sobre o adubamento do solo dos berços e sobre a inversão do solo inferior com o superior. A seguir, parte do grupo se mobilizou para preparar as covas. As mudas foram plantadas com as mãos e conforme esquema projetado no anteprojeto paisagístico (Figura 1).

Por sugestão do professor $\mathrm{V}$, as covas foram forradas com serrapilheira, que havia em abundância por perto. Devido à alta temperatura, a primeira rega foi adiada para o final do dia. A comunidade do "América" se comprometeu a realizar todas as regas previstas para os primeiros 90 dias.

A integração da primeira atividade prática de recuperação da nascente ao "Dia D" simbolizou a adesão da comunidade escolar à revitalização da área. Pela primeira vez, educandos, educadores e familiares se mobilizaram para salvar a nascente.

Figura 1: Plantio participativo.
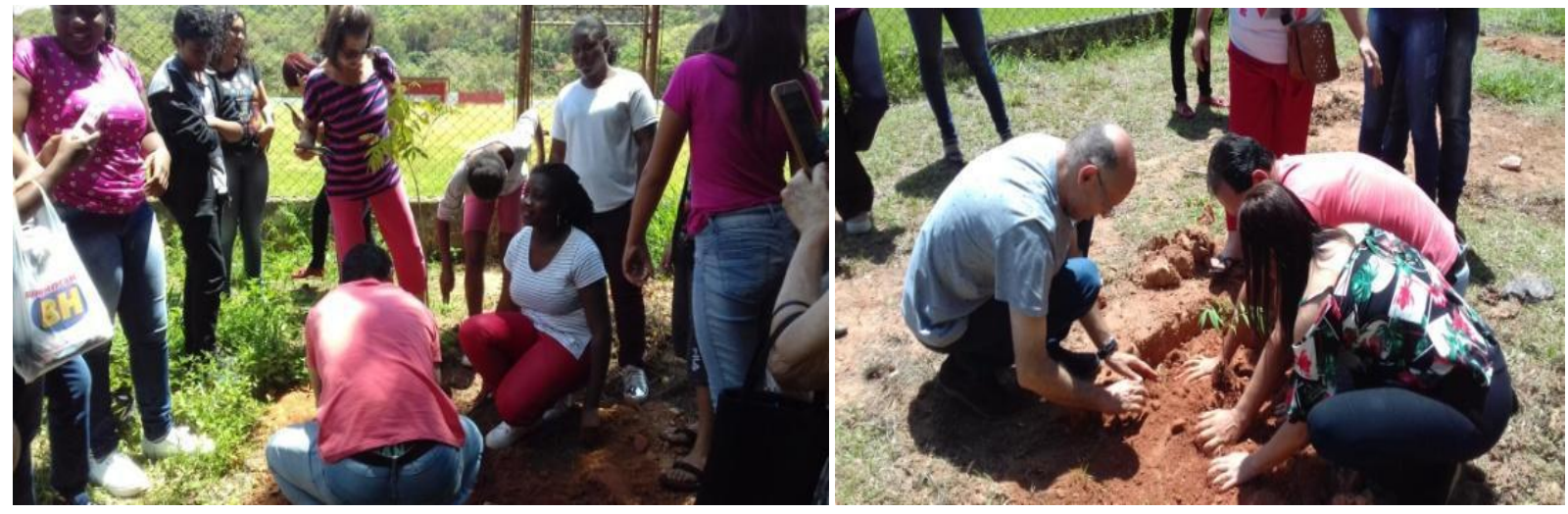

Fonte: Autores (2019) 


\section{Um conflito próximo a nascente}

Quatro dias após o plantio das mudas no entorno da nascente, um boato mobilizou as comunidades envolvidas. A direção escolar do Polivalente informou por telefone à pesquisadora que Sr. M. temia alguns frequentadores do campo viessem a destruir parte das mudas plantadas no "Dia D". O plantio teria invadido uma área utilizada para aquecimento dos atletas. O mesmo servidor público apontado pela população como responsável pelo episódio da aragem dos fundos do campo procurou pessoalmente a direção da escola estadual para defender o uso área ciliar da nascente como espaço para o aquecimento de atletas.

Pouco mais tarde, no mesmo dia, na área da nascente, em conversa com a pesquisadora, Sr. M. negou que a comunidade do "América" estivesse ameaçando a nascente. Ele esclareceu que o risco era oferecido por garotos de um bairro de habitações populares que eventualmente usam a área para a disputa de "peladas". Sr. M. fez questão de mostrar que reforçou a cerca em torno do olho d'água. Contudo, também não se mostrou satisfeito com replantio da mata ciliar da nascente "no espaço para aquecimento dos atletas". Ao expressar seu descontentamento, em tentativa de argumentar a antiguidade daquele uso do espaço, o Sr. M. revelou que há poucos anos uma terraplanagem na área soterrou o olho d'água original da fonte, criando as circunstâncias para o uso da área pelos atletas. Devido a esta interferência, notório crime ambiental, a nascente deixou de ser pontual e passou a ser difusa. Por parte do América, se diz que a terraplenagem foi realizada na mesma época das obras da cobertura da quadra da escola estadual. Na escola não há registro de qualquer iniciativa, até porque a área está cedida ao clube desportivo. A rememoração do crime ambiental repisou o problema da fragilidade do controle institucional sobre o terreno da nascente.

Ao episódio da visita do servidor público, a escola reagiu através da Superintendência Regional de Ensino de Varginha, que notificou à agremiação esportiva sobre o estatuto legal da APP ora sob sua posse.

\section{Apresentação da revitalização da nascente à comunidade desportiva}

No sábado 19 de outubro de 2019, dezenas de jovens entre sete e dezessete anos, que jogam futebol pelo América Futebol Clube, se reuniram na área próxima a nascente para conhecer o projeto de revitalização. Tratava-se da segunda etapa do curso de extensão comunitária que integra a pesquisa. A maior parte dos interessados era pré-adolescente, entre os quais havia alunos da Escola Municipal Clóvis Salgado, situada em frente à escola Godofredo Rangel. Um dos desportistas, também aluno da escola estadual, havia participado do plantio no "Dia D". Alguns familiares dos garotos e o treinador da agremiação participaram das atividades, totalizando um público de 29 pessoas adultas.

A palestra abordou: (i) os principais conceitos relativos à revitalização da nascente; (ii) as características e qualidades do manancial; (iii) as questões ecológicas fundamentais para a intervenção; (iv) os principais relatos colhidos na vizinhança a respeito da história da nascente. Na sequência os participantes foram informados a respeito do trabalho de recomposição vegetal da mata ciliar da nascente.

$\mathrm{Na}$ atividade final da reunião houve um debate sobre o batismo e o uso da nascente em torno do mesmo questionário com três perguntas aplicado na escola estadual. Foram sugeridos nomes e medidas similares aos colhidos junto aos discentes da escola. A receptividade dos atletas amadores infantis foi mais calorosa que a dos demais públicos envolvidos no processo. Diante da questão "a APP da nascente pode ser utilizada para benefício próprio?", surgiram respostas possessivas como "Sim. Apenas para o América" e "Não mexer no campo". Tais respostas devem ser encaradas levando-se em consideração a idade do público.

Após a apresentação, o Sr. M. chamou o Sr. J para conversar com a pesquisadora. Ele promoveu diversos manejos benfazejos na área da nascente, tais como a escavação no aterro na tentativa de reencontrar o olho d'água original e de implantar uma horta comunitária no entorno. Foi um contato importante, pois trata-se de uma pessoa ligada afetivamente à comunidade desportiva e interessada no aspecto ambiental da área.

\section{Apresentação aos professores do anteprojeto da revitalização da nascente}

$\mathrm{Na}$ reunião pedagógica do dia 11 de novembro aconteceu a última atividade de extensão comunitária participativa do projeto. Com presença de cerca de 30 professores, a localização da nascente no terreno da escola foi reafirmada, para assegurar que todos pudessem situá-la. Com auxílio de gráficos e croquis, foram apresentados os estudos com diagnósticos da APP e do entorno. E os professores debateram, ainda que brevemente, o sistema de vegetação, de regeneração natural e de enriquecimento e implantação ecológica. Eles também foram apresentados aos diversos setores formulados para a revitalização da área: a pracinha, o bosque, a área de regeneração natural e a área de convivência a ser instalada próximo às quadras da escola. 
Houve um interesse particular pelas imagens de referência dos mobiliários feitos com troncos de árvore, pneus e encordoamentos, que foram considerados como uma solução criativa e viável. Os professores também contribuíram com sugestões, principalmente com relação aos espaços da escola a serem revitalizados. Ficou patente que visualizar projetivamente a revalorização da área intensificou o sentimento de pertencimento da comunidade docente.

\section{UM PROJETO PAISAGÍSTICO SUSTENTÁVEL}

No contexto das iniciativas sustentáveis, Oliveira e Monteiro (2015) destacaram o "paisagismo sustentável" como uma vertente que promove a qualidade da interface entre o natural e o fabricado, entre os recursos naturais e a humanidade. Por exemplo, os jardins sustentáveis são concebidos para replicar as características de um ecossistema vivo, de tal forma que eles demandam pouca manutenção e estimulam a biodiversidade. Eles se utilizam de espécies nativas, o que contribui para a racionalidade no uso da água e para a boa relação com a fauna típica.

No projeto desenvolvido, os tipos de vegetações existentes foram levantados e sistematizados na Figura $2 \mathrm{~A}$. Quanto aos gradientes de umidade do solo, a partir de três visitas à área da nascente, em 2018, se observou que o solo se apresentou todo seco. Em janeiro de 2019, ele apresentou umidade em alguns pontos. Em março de 2019, na data da análise macroscópica, três gradientes de umidade puderam ser observados: encharcado, úmido e drenado (FIGURA 2B).

De acordo com o estudo preliminar para o zoneamento, em conformidade com o Código Florestal (BRASIL, 2012), o campo do América e as quadras do polivalente foram classificados como áreas urbanas consolidadas. Ainda que sejam de grande utilidade para a comunidade, elas não podem ser manejadas de modo que resulte em dano ambiental. A área entre os limites citados na caracterização da nascente foi setorizada da seguinte forma: área de regeneração natural cercada, que por sua vez foi subdividida em área sujeita a encharcamento e área drenada dentro da APP; bosque, área de implantação total de vegetação, e o talude onde, em parte houve a introdução de bambu cana da índia e outra parte apresenta presença de capoeira (dentro da APP); pracinha, área fora dos limites da APP, que oferece acesso direto ao logradouro público. Acima do talude, em branco, estão os corredores entre o muro projetado e as quadras. O encontro do corredor da quadra coberta e o corredor das quadras descobertas formam um "triângulo" ideal para a convivência dos usuários ao ar livre (FIGURA 3A).

O setor de regeneração natural deve ser cercado e seus acessos monitorados por cuidadores da nascente. Dentro desse setor, será ainda cercada a área sujeita a encharcamento, para proteger os cuidadores e possíveis visitantes de atolamento. Os dois outros setores, bosque e pracinha, poderão ser utilizados pela comunidade para educação e lazer, com atividades de baixo impacto ambiental. O sistema de revegetação (Figura 3B) foi sistematizado em três classes: "implantação", indicada para o caso de alteração profunda nas características originais da área; "enriquecimento", para áreas com perturbação mediana, que conservam algumas das características originais; e "recuperação natural", para áreas pouco perturbadas, que mantém a características originais e precisam de isolamento, para propiciar os processos naturais de sucessão ecológica (BARRETO, 2010).

Figura 2: Croquis representando os tipos de cobertura do solo (A) e os gradientes de umidade do solo no entorno da nascente (B).

(A)

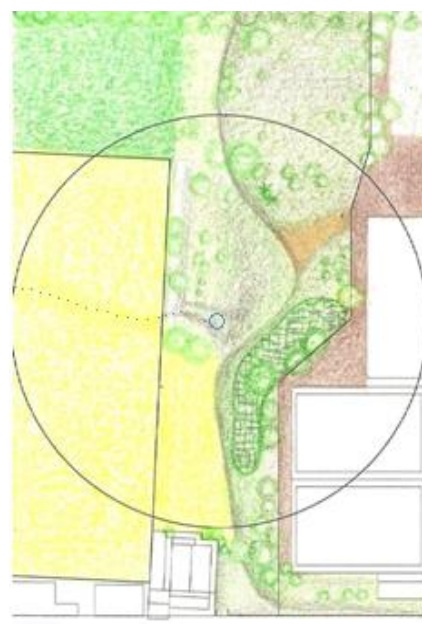

Aterro gramado

Campo limpo

Solo descoberto compacto

(Phyllostachys aurea)

Capoeira

Espécies arbóreas

Solo descoberto assoreado

Olhos d'água

Percurso canalizado da água
(B)

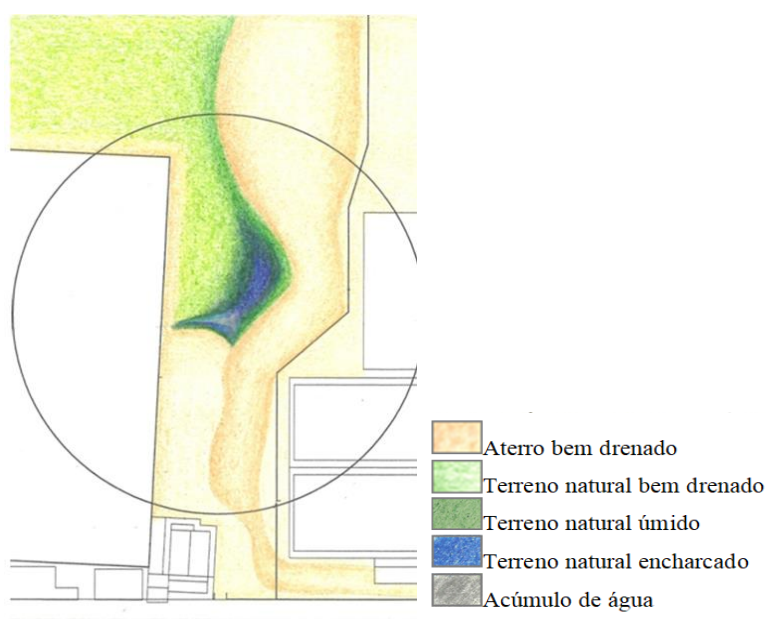

Fonte: Keler Mara Gomes de Resende. 
Figura 3: Croquis com zoneamento e principais acessos (A) e croquis com sistemas de revegetação (B).

(A)

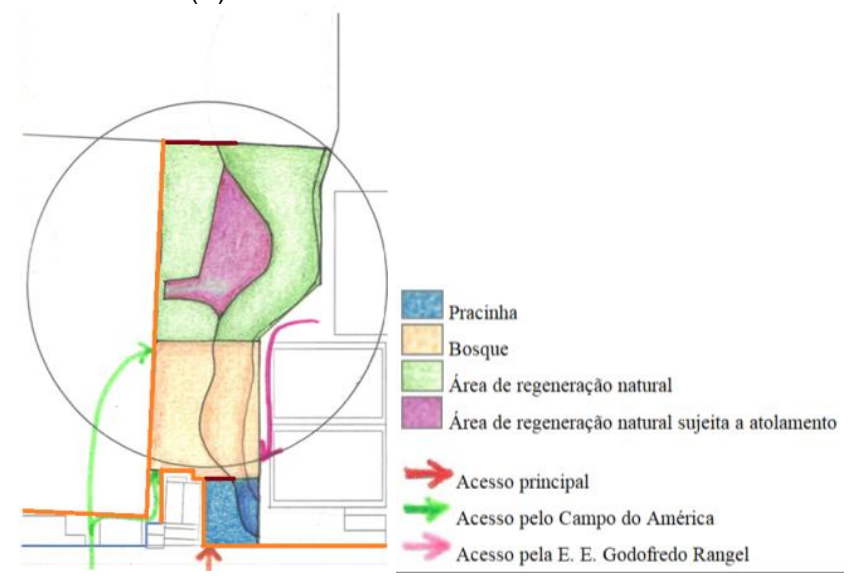

(B)

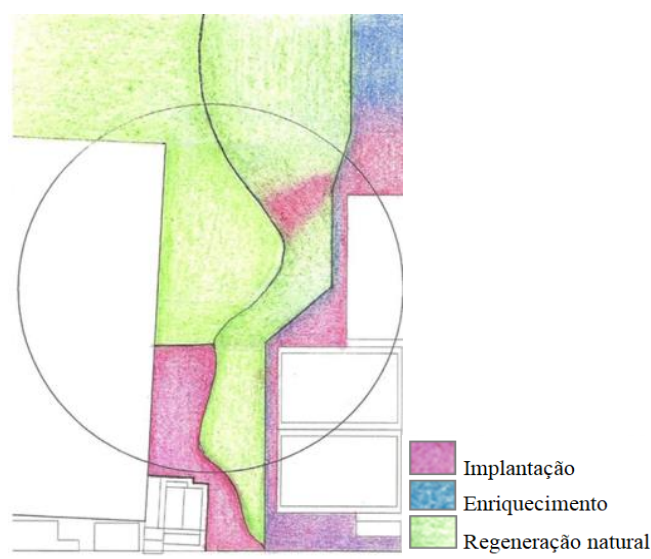

Fonte: Keler Mara Gomes de Resende.

$\mathrm{Na}$ área cercada, onde se localizam os olhos d'água, a vegetação foi considerada perturbada, com presença de capoeira, portanto optou-se pelo sistema de regeneração natural, tanto na zona de solo sujeito a encharcamento quanto na parte de solo drenado, exceto pela área de solo assoreado, que necessita de implantação de vegetação.

No setor chamado de bosque, na parte plana, onde existe gramado, optou-se pelo sistema de implantação de espécies arbóreas nativas. No talude, em parte houve a introdução de bambu, provavelmente para proteger o solo com inclinação muito acentuada contra assoreamento, e no restante existe vegetação perturbada, com capoeira. Por isso, no talude da parte denominada bosque, optou-se pelo sistema de regeneração natural. Na zona denominada pracinha, na área plana, existe vegetação rasteira e o sistema de revegetação escolhido foi também a implantação. Nos corredores das quadras da escola, que é área de recarga da nascente, foi sugerido o sistema de implantação e de enriquecimento, com árvores nativas na APP e espécies a serem estudadas junto à comunidade escolar, no restante.

Quanto ao Anteprojeto (Figuras 4A e 4B), a partir da eleição pelas comunidades dos usos sustentáveis possíveis para a região da nascente, foi elaborada uma previsão do mobiliário e de equipamentos necessários, com sugestão de materiais e de técnicas sustentáveis (ambiental, social e economicamente).

Foram delimitados o perímetro da pracinha e suas características, e a área destinada ao plantio da vegetação - forração, trepadeiras e árvores - foi demarcada na planta de implantação. Também foi elaborado um projeto para a revegetação do Bosque, considerando-se a necessidade de recompor a área degradada, as características/peculiaridades do bioma local, o tipo de solo e as espécies disponíveis no Horto Municipal. A proposta para o bosque foi apresentada no formato de Anteprojeto (Figura 4 A).

Figura 4: Representação gráfica do Anteprojeto da parte frontal $(A)$ e posterior $(B)$ da área da nascente.

(A)

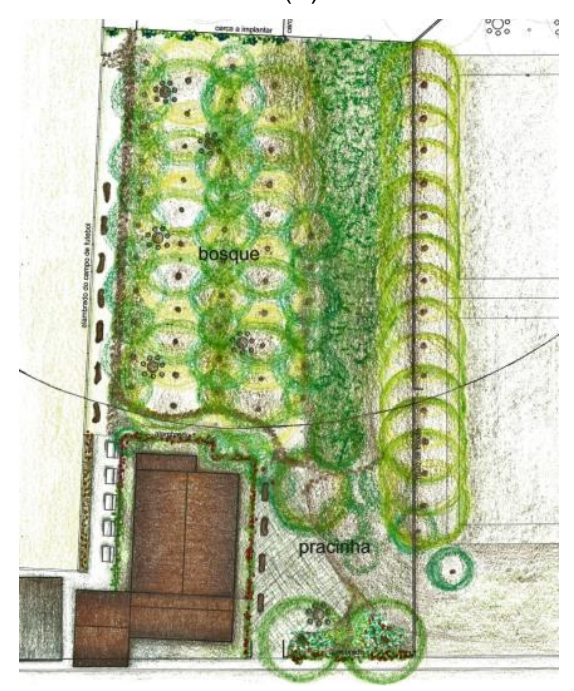

(B)

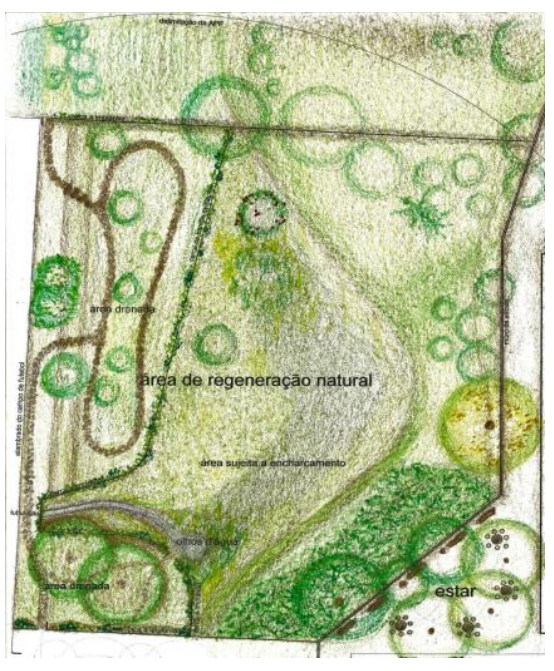

Fonte: Keler Mara Gomes de Resende. 
Resende, K. M. G; Alcantra, E; Marques, R. F. P. V; Rios, M. R. D. L.

O método escolhido para a revegetação da área do bosque, que conta com $600 \mathrm{~m}^{2}$, foi a regeneração artificial por plantio de mudas, obedecendo o estágio sucessional da floresta. Conforme a avaliação do solo e as espécies indicadas, o espaçamento determinado para área foi de $4 \mathrm{~m}$ entres as fileiras é de $3 \mathrm{~m}$ entre as mudas. Considerando a área total do bosque e o espaçamento entre as mudas propostas, chegou-se ao plantel necessário de 50 mudas, às quais deve-se somar a quantidade estimativa extra de $15 \%$, relativa às perdas, totalizando 58 mudas.

O modelo de plantio escolhido foi o misto, com composição florística de $50 \%$ das plantas de espécies pioneiras, $30 \%$ das plantas de espécies secundárias e $20 \%$ de espécies clímax. As plantas foram distribuídas em linhas alternadas, no plantio em quincôncio. A especificação das espécies para todas as demais áreas delimitadas consta no projeto botânico. Tal modelo de plantio e composição florística obtiveram bons resultados em experimentos (BOTELHO et al.,1995; BOTELHO; DAVIDE; FARIA,1996; PEREIRA et al., 1999; PINTO, 2003).

$\mathrm{Na}$ fase de projeto executivo, foi elaborada primeiramente uma planta de implantação dos elementos não vegetais (Figura 5A) a partir da qual foi elaborada a planta de implantação botânica (Figura 5B). Para marcar a entrada principal, optou-se pelo uso de dois ipês (Handroanthus chrisotricha e Handroanthus impetiginosus), um amarelo, e outro roxo, ambos na pracinha, próximo ao portão. Trepadeiras, conhecidas como cipó-deSão-João (Pyrostegia venusta), foram previstas para cobrir parcialmente os alambrados da entrada, assim como os que cercam a edificação abandonada. Herbáceas e forrações serão utilizadas nos canteiros da pracinha. Próximo aos bancos existentes entre a edificação abandonada e o alambrado do campo de futebol já existem cosmos amarelos. Junto aos existentes, foram representados os novos, que serão adicionados através de semeadura.

Figura 5: Planta de implantação de elementos não vegetais (A) e planta de implantação botânica (B).

(A)

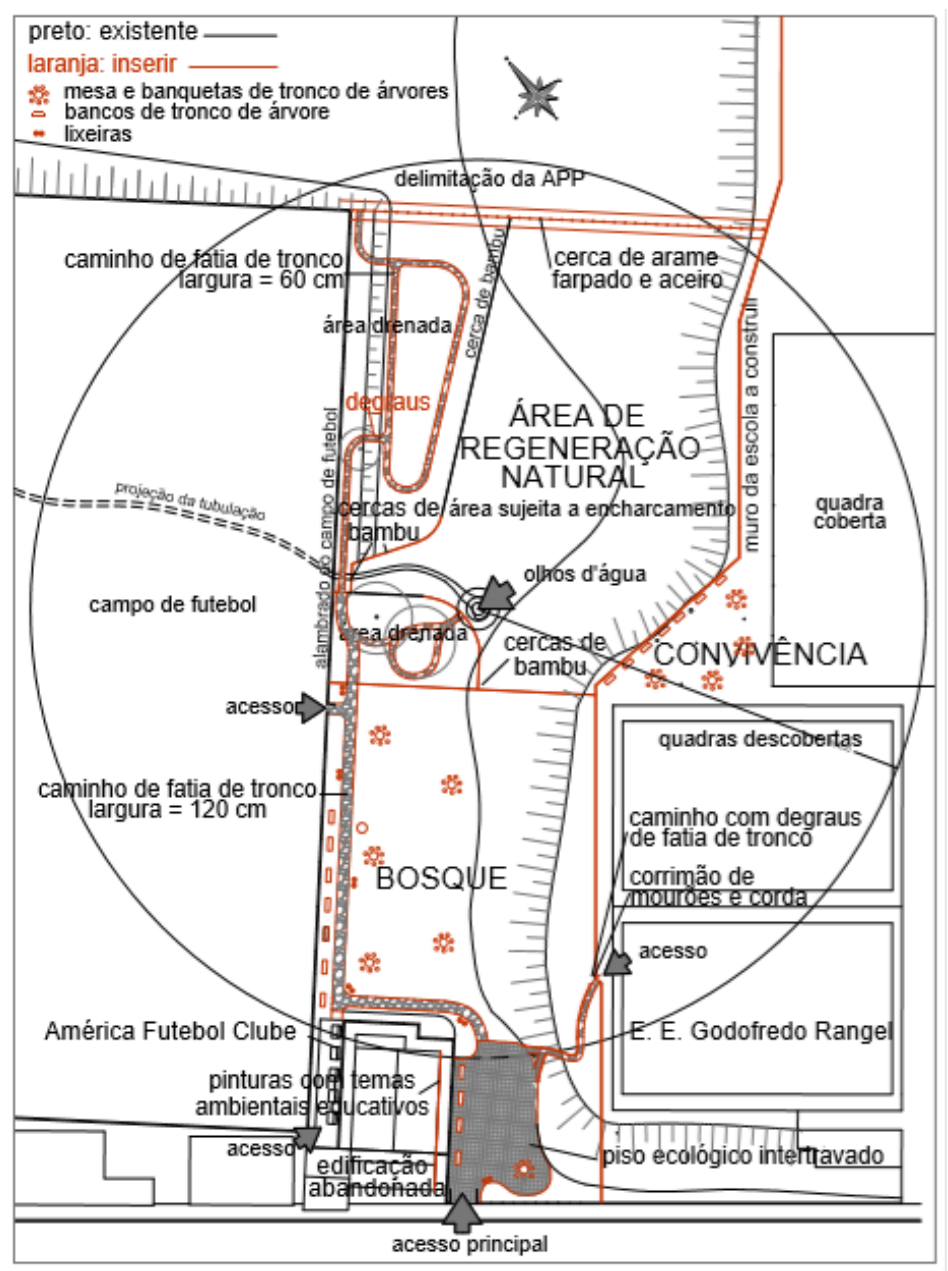

(B)

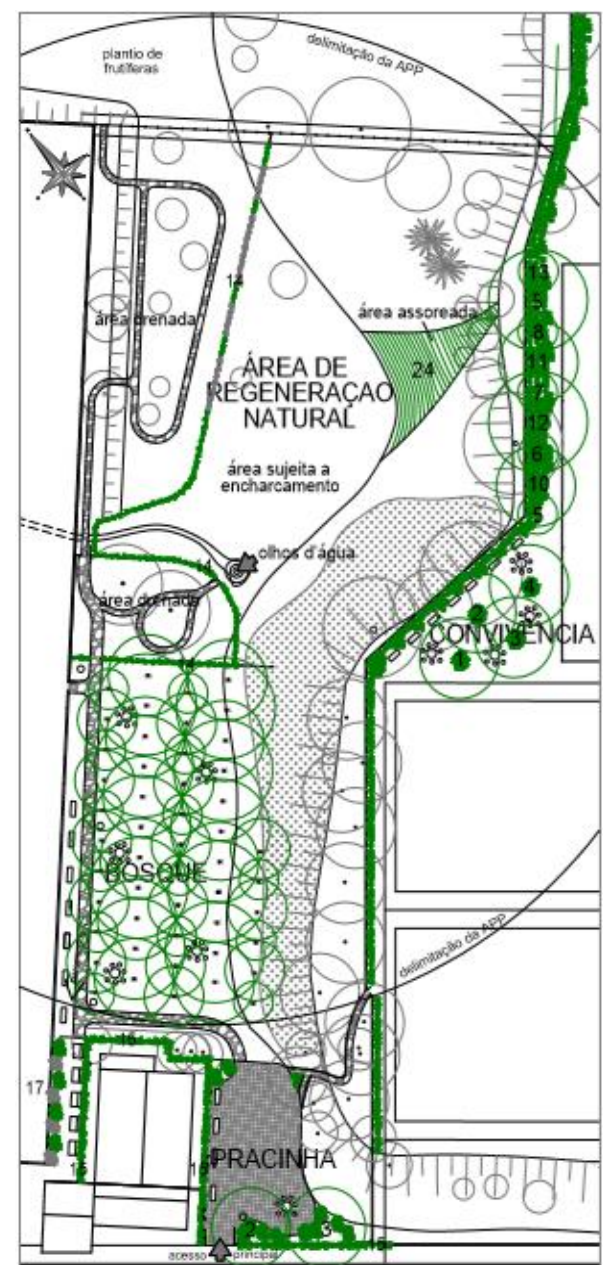

Fonte: Keler Mara Gomes de Resende. 
$\mathrm{Na}$ área de regeneração natural, em alguns pontos da cerca existente há uma trepadeira espontânea, de flores azuladas, Ipomea cairica. A intenção é manejar esta trepadeira para que ela cubra o restante das cercas. Nesta área, a única inserção vegetal será de capim vetiver, Vetiveria zizanioides, que tem eficácia reconhecida contra o assoreamento de taludes (ANDRADE, 2013). Seu plantio será feito logo após o início da estação chuvosa, em cordões de vegetação em nível, com espaçamento entre plantas de $15 \mathrm{~cm}$ e a adubação será feita com o uso de esterco e fontes naturais de fósforo e potássio. Nos corredores que se formarão entre as quadras e o muro a ser construído, sugere-se o plantio de Syngônium angustatum, por ser nativa, ter a capacidade de crescer à meia sombra rapidamente propiciando a proteção do solo, a umidade $e$ escoamento lento da água das chuvas. $\mathrm{Na}$ área de convivência, na escola, próxima às quadras, foram adicionadas quatro espécies de ipê: branco - Handroanthus róseo-alba, amarelo - Handroanthus chrisotricha, roxo - Handroanthus impetiginosus e rosa - Handroanthus heptaphyllus, por serem nativas e muito decorativas, formando um foco de interesse neste ponto. Próximo aos troncos dos ipês serão plantadas mudas de lambari, Tradescantia zebrina, para ajudar a proteger e a permeabilizar o solo desta área, que é muito compactado. Sua cor verde-arroxeada contrastará com o verde claro do Syngônium angustatum ao longo do muro. Além da cerca posterior, ao fundo da nascente e do campo de futebol, sugeriu-se o plantio de frutíferas nativas ou bem adaptadas à esta região.

O projeto paisagístico apresentado contempla, principalmente, a área da APP da nascente do Polivalente que é a parte que necessita de interferência com urgência. A área determinada "pracinha", embora não pertencente à APP, também foi trabalhada aqui por tratar-se da área de acesso principal à nascente. Foram feitas sugestões a serem detalhadas num outro momento, junto à comunidade escolar, como plantio de frutíferas nativas atrás da quadra coberta, enriquecimento vegetativo nos taludes do campo de futebol da escola e ao redor da antiga pista de corrida, recuperação do piso desta pista com material permeável, etc. Essas medidas, além de promoverem maior permeabilidade, darão utilidade a tais espaços, o que pode evitar que o solo seja impermeabilizado mais tarde.

A experiência de localizar, nomear e propor a recuperação de uma nascente urbana, através de um plano participativo, foi enriquecedora sob diversos aspectos. Proporcionou um contato próximo com a interface em que se articulam legislação, técnicas ecológicas e de paisagismo e a cultura das comunidades afetadas, demonstrando assim como é complexa e multifacetada a problemática das águas no Brasil. Além disto, o fato de se tratar de uma nascente localizada em área pública pertencente ao Estado de Minas Gerais permitiu que a proposta ecoasse nos canais burocráticos da máquina pública, proporcionando o contato com receptividade e as dificuldades de circulação do discurso ambientalista nas engrenagens do poder público.

A discussão e os resultados aqui apresentados demonstraram que a questão ambiental (em geral) e a proteção das nascentes (em particular) ainda ocupam um lugar bastante lateral no senso comum e nas ações do Estado. Neste sentido, é eloquente que tenha havido, por exemplo, rumores sobre possíveis agressões à nascente mesmo após o início do processo de recuperação, além da militância deliberada contra ela, que teria sido praticada junto da diretoria da escola estadual por um funcionário da municipalidade. Como se viu, estar em área pertencente ao poder público pouco colabora para assegurar à nascente as melhores condições ecológicas.

\section{CONCLUSÃO}

O processo participativo de construção de soluções gerou engajamento comunitário e medidas administrativas da diretoria escolar em favor da nascente. O projeto paisagístico, respeitando a legislação vigente e prezando pela boa técnica de reflorestamento, propôs um produto economicamente viável, sustentável, urbanisticamente correto e, portanto, com potencial para recompensar o Estado de Minas Gerais, proprietário da área, com a legislação ambiental nacional.

Há impasses que devem ser sopesados. Uma das maiores dificuldades que se impõe diz respeito à falta de espaço na agenda de uma instituição escolar pública mineira para as questões ambientais de sua própria paisagem. O fato de não ter havido mudanças significativas nas rotinas da escola a partir do início dos debates sobre a nascente demonstrou a baixa permeabilidade institucional ao tema. Muito embora o apoio de ordem pessoal tenha sido imediato e intenso, foi necessário pegar carona em agendas escolares preestabelecidas para mobilizar professores e alunos. Um quadro sintomático do lugar lateral do debate ambiental, mesmo nas instituições escolares, e que sem dúvida limitou os resultados sociais desta pesquisa.

O projeto apresentado representa, não só uma revitalização possível do espaço, mas também a necessária mitigação de um dano ambiental já produzido.

Para finalizar, anote-se que a efetivação da revitalização da nascente, que não era considerada até o início das ações de campo desta pesquisa, ganhou um impulso fundamental para que se efetive, tornando-se um 
problema vivo para associação desportiva e escola estadual. O que permite concluir que a investigação teve efetividade social e ambiental.

\section{REFERÊNCIAS}

ASSOCIAÇÃO BRASILEIRA DE NORMAS TÉCNICAS (ABNT). NBR 16636-2: Elaboração e desenvolvimento de serviços técnicos especializados de projetos arquitetônicos e urbanísticos, Parte 2: Projeto arquitetônico. ABNT-CB $002,2017$. Disponível em: http://www.caubr.gov.br. Acesso em: 09 de out. 2019.

BARBOSA, E. M.; MOTA, T. C. Direito ambiental e gestão participativa. 2013. Disponível em: https://carollinasalle.jusbrasil.com.br/artigos/112210588/direito-ambiental-e-gestao-participativa. Acesso em: 20/11/2019.

BARRETO, S. R.; RIBEIRO, S. A.; BORBA, M. P. Nascentes do Brasil: Estratégias para a proteção de cabeceiras em bacias hidrográficas. 1 ed. São Paulo: WWF - BRASIL, 2010.

BOtElHO, S. A.; DAVIDE, A. C.; PRADO, N. J. S.; FONSECA, E. M. B. Implantação de Mata Ciliar. Belo Horizonte: CEMIG/UFLA/FAEPE, 1995. 36 p.

BOTELHO, S. A.; DAVIDE, A. C; FARIA, J. M. R. Desenvolvimento inicial de seis espécies florestais nativas em dois sítios, na região sul de Minas Gerais. Cerne, Lavras, v. 2, n. 1, p. 43-52, 1996.

BRASIL. Lei federal no. 12.651/12. Código florestal. Disponível em: http://www.planalto.gov.br. Acesso em: 12 mar. 2019. CAPRA, F. As conexões ocultas: Ciência para uma vida sustentável. Ed. Cultrix. São Paulo, 2002.

OLIVEIRA, D. F.; MONTEIRO, L. V. G. Ecodesenvolvimento: Uma Abordagem sob o Contributo de Ignacy Sachs. Revista de Direito, Economia e Desenvolvimento Sustentável, v. 1, n. 1, p.29-48, 2015.

PEREIRA, J. A. A.; BOTELHO, S. A.; DAVIDE, A. C. Desenvolvimento de espécies florestais de rápido crescimento em diferentes condições de sítio visando a recomposição de matas ciliares. Cerne, Lavras, v. 5, n. 1, p. 36-51, 1999.

PEREIRA, P. V. V; MATOS, L. S. Lazer como mecanismo de apropriação democrática dos espaços públicos: um estudo sobre as práticas de lazer na Estação das Docas em Belém (Pará, Brasil). Turismo \& Sociedade, Curitiba, v. 8, n. 3, p. 511-531, 2015.

PINTO, L. V. A. Caracterização física da sub-bacia do Ribeirão Santa Cruz, Lavras, MG, e propostas de recuperação de suas nascentes. Dissertação (Mestrado). Programa de Pós-graduação em Ciências Florestais. Lavras, MG: Universidade Federal de Lavras (UFLA), 2003.

RAMALHO, D. Rio Tamanduateí - Nascente à Foz: percepções da paisagem e processos participativos. Paisagem Ambiente. São Paulo, n. 24, p. 99-114, 2007.

VIEIRA, W. M. Análise das terminologias utilizadas para a recuperação de cursos d'água urbano. 87 p.; Dissertação (mestrado). Programa de pós-graduação em Sociedade, Tecnologia e Meio Ambiente. Anápolis: Centro Universitário de Anápolis (UniEvangélica), 2019.

NOTA DO EDITOR (*): O conteúdo do artigo e as imagens nele publicadas são de responsabilidade do(s) autor(es). 